\title{
IDENTIFICAÇÃO DOS RISCOS QUÍMICOS NO PROCESSO DE SOLDAGEM E SUAS MEDIDAS DE PROTEÇÃO
}

\author{
BARROS, João Pedro Alves de Azevedo ${ }^{1}$ \\ MORAIS, Márcia Vilma Gonçalves ${ }^{1}$
}

RESUMO: A indústria possui muitas atividades que tornam o ambiente insalubre para os empregados, sendo entre elas a soldagem umas das que se destacam com exposição a agentes químicos e físicos. Nessa atividade, o profissional está exposto a partículas em suspensão (aerodispersóides) de metais, conhecidos como fumos metálicos, estes são resíduos provenientes da solda e podem ser constituído principalmente de zinco, níquel, manganês, cobre, alumínio, ferro, cádmio, chumbo e cromo. Quando dispersos no ambiente de trabalho podem ser respirados pelo empregado e causar danos à saúde. O intuito deste trabalho é realizar uma análise dos componentes e limites máximos das legislações brasileira e internacional para os fumos metálicos, apresentando as doenças relacionadas com a atividade e as medidas de controle para reduzir a exposição do trabalhador e/ou tornar o ambiente salubre.

Palavras-chaves: Fumos metálicos. Soldagem. Agente químico.

SUMMARY: The industry has many activities that make the environment unhealthy for employees, including welding among which stand out with exposure to chemical and physical agents. In this activity, the professional is exposed to suspended particles (aerodispersoides) of metals, known as metallic fumes, these are residues coming from the weld and may consist mainly of zinc, nickel, manganese, copper, aluminum, iron, cadmium, lead and chrome. When dispersed in the work environment can be breathed by the employee and cause health damage. The aim of this work is to perform an analysis of the components and maximum limits of Brazilian and international legislation for metallic fumes, presenting the diseases related to the activity and control measures to reduce worker exposure and / or make the environment healthy.

Keywords: Metal fumes. Welding. Chemical agent.

\section{INTRODUÇÃO}

$\mathrm{Na}$ indústria e nas diversas áreas da construção existem muitos riscos para os trabalhadores, principalmente físicos, biológicos, mecânicos, ergonômicos e químicos. Uma das atividades que mais causa danos à saúde dos trabalhadores é a atividade de soldagem. Para exercer essa atividade o trabalhador fica exposto principalmente ao risco físico e químico com mais intensidade.

O soldador está exposto a risco físico de radiação não ionizante e ruídos, enquanto para o risco químico se enquadra os fumos e gases. Estes trabalhadores ficam expostos a resíduos químicos da solda que ficam dispersos no ar, sendo chamados de "fumos e/ou gases metálicos".

Estes fumos metálicos podem causar sérios problemas na saúde dos trabalhadores, dependendo da impureza, concentração e intensidade destes gases e fumos.

Neste trabalho será focado na exposição ao risco químico, tendo como objetivo apresentar os danos à saúde dos trabalhadores e as melhores medidas de proteção individual e coletiva para que os riscos sejam eliminados ou atenuados, visando a saúde e a integridade dos trabalhadores.

\footnotetext{
${ }^{1}$ Fundação Educacional de Ituverava - FAFRAM
} 


\section{DESENVOLVIMENTO}

\section{Risco Químico}

De acordo com a Norma Regulamentadora 9 (NR - 9: Programa de prevenção de riscos ambientais) do Ministério do Trabalho, é definido como agente químico qualquer substância que possa penetrar no organismo humano por via respiratória, sendo eles poeiras, fumos, névoas, neblinas, gases ou vapores, ou que, pela natureza da atividade de exposição, possam ter contato ou ser absorvidos pelo organismo pela pele ou por ingestão (BRASIL, 1978c).

Lopes (2007) melhora essa definição do Ministério do Trabalho, relacionando que o agente químico na forma de partícula, conhecidos como aerodispersóides são partículas sólidas (poeiras, fumaças e fumos metálicos) ou líquidas (névoas e neblinas) com tamanho inferior a $100 \mu \mathrm{m}$. Entretanto, possuem massa muito pequena e ficam em suspensão no ar, nem a ação da gravidade é capaz de provocar a deposição destas partículas de forma imediata, sendo necessário horas para a deposição em um ambiente sem perturbações (variações da velocidade do ar, da temperatura, de pressão ou mesmo o funcionamento de máquinas e etc.).

Os agentes químicos que colocam em risco a saúde e a integridade do empregado, no processo de soldagem, são constituídos em sua maioria por substâncias dos fumos metálicos. Estes fumos são lançados no ambiente de trabalho, contaminando-o, podendo ter contato com o empregado de diversas formas, causando sérios danos à saúde.

Desde as décadas de 1970 e 1980, os fumos metálicos foram considerados um dos maiores problemas para a saúde ocupacional, pois além das diversas patologias e de problemas respiratórios, podem causar também câncer pulmonar (COLACIOPPO, 1985).

\section{Processo de soldagem}

O processo de soldagem se baseia em unir duas ou mais partes metálicas, formando uma nova parte, onde se possa assegurar a continuidade do material e as propriedades químicas e mecânicas deste novo conjunto (MAGRINI, 1999). Neste processo de soldagem, utiliza-se uma fonte de calor, de pressão ou de forma simultânea entre ambas, onde o resultado seja a solda (MAESTRI;VITALI, 2005).

O processo de soldagem é muito utilizado nos vários segmentos da indústria, abrangendo uma grande quantidade de materiais e produtos (componentes químicos envolvidos na operação).

De acordo com Kadefors e Laring (1997) são classificados em três os equipamentos necessários para o processo de soldagem sendo estes: equipamentos de processo (tochas, esmerilhos, contador a gás etc., assim como a infra-estrutura para o abastecimento destes equipamentos com energia ou material de suporte); equipamentos de apoio (equipamento para transporte e posicionamento de peças e ferramentas) e equipamento ambiental (exaustores, insufladores, materiais absorventes de ruído). As máscaras de soldagem estão incluídas neste último item, bem como as cortinas de proteção.

A tocha é um dos elementos principais do soldador, sendo este o que realiza a solda. A tocha é alimentada por um cabo de energia elétrica e de gás (no processo de soldagem MIG/MAG também é utilizado um eletrodo consumível). Alguns tipos de tochas têm acoplado um sistema de exaustão de fumos, mas este aumenta o peso do equipamento, atrapalhando o conforto do empregado e dificultando assim o seu uso (SILVA, 2003).

\section{Composição dos fumos metálicos}

Os subprodutos da soldagem se referem aos resíduos ou emissões, podendo ser tanto da energia (na forma de calor e/ou radiação), quanto de partículas e gases. Estes representam desperdícios 
provenientes da atividade e que por consequência são dispersos no ambiente, havendo assim a sua contaminação e prejudicando a saúde dos trabalhadores nas proximidades (SILVA, 2003). Dentre os riscos da atividade de soldagem, a exposição a fumos metálicos se destaca como sendo o mais nocivo (ANTONINI, 2003).

A dispersão do resíduo da solda no meio ambiente e a quantidade vão depender de alguns fatores, principalmente em relação ao material base e seu revestimento, processo de soldagem, composição e revestimento do eletrodo, composição do gás de proteção, tipo de alimentação da máquina de soldagem, voltagem e amperagem, ou seja, os parâmetros de soldagem (SILVA, 2003). Sendo que estes parâmetros são determinados de acordo com a quantidade de solda requerida e o custo. Entretanto, devido à mudança na legislação e ao aumento no rigor da fiscalização, vem se preocupando com a contaminação do ambiente do trabalhador, para que a saúde destes não seja prejudicada.

$\mathrm{Na}$ execução do processo de soldagem ocorre a vaporização e o derretimento do eletrodo consumível. Este metal, quando vaporizado, se condensa e forma assim partículas sólidas suspensas (com diâmetro de 0,01 a 1,00 $\mu \mathrm{m}$ ), sendo assim definidos como fumos metálicos (LYTTLE, 1999).

Parte da composição das partículas formadas provém do revestimento do metal, como tintas, óleos e camadas de outros metais (metal galvanizado), aumentando significativamente a geração de resíduos no ambiente (GAREIS, 1994; HEWITT, 1999). Entretanto, de 85 a 90\% dos fumos emitidos são provenientes dos consumíveis da solda (LUCAS e CARTER, 1999; LYTTLE, 1999; HEWITT, 1999), mas alguns elementos podem ser formados durante o processo de solda por reação dos componentes envolvidos no processo (LYTTLE, 1999).

Assim, os principais componentes presentes no processo de soldagem que afetam a saúde dos trabalhadores são: zinco, níquel, manganês, cobre, alumínio, ferro, cádmio, chumbo e cromo (SILVA, 2003; COLACIOPPO, 1985). Outras substâncias são encontradas no processo de soldagem, como o gás ozônio (forma instável do gás oxigênio), óxido de nitrogênio, dióxido de nitrogênio, dióxido de carbono e monóxido de carbono (ANTONINI, 2003; GAREIS, 1994; AIHA, 1984), sendo os dois últimos gases classificados como asfixiantes (COLACIOPPO, 1985).

No quadro 1, são mostrados os componentes presentes em vários processos de soldagem (fumos de solda), uma vez que a composição dos fumos e gases depende do tipo de soldagem e dos materiais utilizados.

Quadro 1 - Classificação dos componentes presentes nos vários tipos de processo de soldagem.

\begin{tabular}{|c|l|l|}
\hline \multirow{2}{*}{$\begin{array}{c}\text { Material } \\
\text { Particulado }\end{array}$} & $\begin{array}{l}\text { Irritantes pulmonares } \\
\text { e Tóxicos Sistêmicos }\end{array}$ & $\begin{array}{l}\text { Cádmio, Cromo, Chumbo, Fluoretos, } \\
\text { Manganês, Mercúrio, Níquel, Titânio, } \\
\text { Vanádio, Zinco. }\end{array}$ \\
\cline { 2 - 3 } & Pneumoconiogênicos & $\begin{array}{l}\text { Alumínio, Carbono, Berílio, Estanho, Ferro, } \\
\text { Sílica, Cobre, Asbesto. }\end{array}$ \\
\hline \multirow{2}{*}{ Gases } & Irritantes & $\begin{array}{l}\text { Ozona, Fosgênio, Óxido de Nitrogênio, } \\
\text { Fosfina. }\end{array}$ \\
\cline { 2 - 3 } & Asfixiantes & $\begin{array}{l}\text { Monóxido de carbono, Dióxido de carbono, } \\
\text { Gases inertes. }\end{array}$ \\
\hline
\end{tabular}

Fonte: Adaptado de Colacioppo, 1985. 
Como exemplo, pode-se considerar o relato de Hewitt (1999), que para certo tipo de processo de soldagem (TIG - Tungsten Inert Gas), produz menor quantidade de fumos em vista da maior presença do gás ozônio, afirmando por este autor que processos onde se produza menor quantidade de gás ozônio formem mais fumos.

Como no quadro 1, os materiais particulados podem ser irritantes/tóxicos, pois estes atingem a mucosa (nariz, faringe e olhos) devido as reações de desnaturação e oxidação, causando lesões e até mesmo edema pulmonar (SOUZA et al., 2004), em alguns casos os materiais particulados causam doenças pneumoconiogênicas (GOLDMAN, 2000).

Os gases e vapores tóxicos podem ser classificados como irritantes, anestésicos e asfixiantes.

Para a classe dos gases irritantes podem dividir em irritantes primários que têm ação local, atuando no sistema respiratório e olhos (causando inflamação, avermelhamento, desidratação, inchaço e até necrose), enquanto que os irritantes secundários podem causar, além dos danos primários tem ação sistêmica, sendo absorvidos e distribuídos pelo organismo (principalmente no sistema nervoso e respiratório).

Os asfixiantes levam à deficiência ou privação de oxigênio, podendo ser asfixiantes simples (gases inertes que afetam na concentração do oxigênio no meio, mas não altera a troca gasosa nos pulmões) e asfixiantes químicos (em pequenas concentrações causam asfixia, pois alterar a troca gasosa). Já as anestésicas, são substâncias que interfere no sistema nervoso central, provocando perda de consciência, parada respiratória e morte (VIDAL;CARVALHO, 2003).

Os gases irritantes do processo de soldagem possuem o mesmo princípio do material particulado, atingindo principalmente a mucosa, enquanto que os asfixiantes diminuem a quantidade (fração) de oxigênio presente, dificultando a captação e distribuição do oxigênio pelo sistema cardiovascular. Sendo os principais o dióxido de carbono que dificulta a captação e o monóxido de carbono que se liga com a hemoglobina e neutraliza a distribuição do oxigênio no organismo, contudo o monóxido de carbono também é considerado como tóxico (SOUZA et al., 2004).

A identificação dos problemas na saúde dos trabalhadores que exercem a atividade de soldador é de grande importância, uma vez que esta atividade acompanhada de falta de treinamento e uso incorreto dos Equipamentos de Proteção Individual (EPI's) representa um risco grave a saúde aos trabalhadores, sendo responsável por problemas respiratórias e doenças que afetam o pulmão (SILVA e SIQUEIRA, 2014).

\section{Normas Regulamentadoras}

A Norma regulamentadora 15 (NR 15 - Atividades e operações insalubres) descreve os valores do limite de tolerância de agentes químicos (Quadro N. 1 do anexo XI), entretanto normas internacionais também são muito utilizadas no Brasil como referência, sendo a principal delas a ACGIH (American Conference of Governmental Industrial Hygienists).

A ACGIH é atualizada anualmente e trás novas pesquisas na área, sempre atualizando e adicionando a sua lista de produtos de risco para o trabalhador. Enquanto que a NR-15 não é modificado com a mesma frequência a lista de produtos químicos nocivos aos trabalhadores desde 1978 (com exceção do benzeno que foi modificado em 1994, criando um anexo mais específico e incluiu o negro de fumo em 1992), desta forma muitas empresas, autores e órgãos utilizam a ACGIH como parâmetro (BRASIL, 1978d).

No Brasil pode-se usar a ACGIH em PPRA (Programa de Prevenção de Riscos Ambientais), mas para determinar insalubridade e laudos de aposentadoria especial deve ser utilizado obrigatoriamente a NR -15 (Anexo 11, 12 e 13). Para utilizar os valores de limite máximo da ACGIH como parâmetro no Brasil, 
deve ser feito uma correção da concentração, pois a ACGIH tem como referência 40 horas semanais ( 8 horas diárias) de trabalho, enquanto que atualmente a jornada brasileira é de 44 horas semanais (8 horas diárias). Contudo os limites de tolerância da NR-15 foram criado em 1978, quando a jornada de trabalho era de 48 horas semanais (8 horas diárias), devendo assim fazer uma correção para utilizar - lá atualmente (PEIXOTO;FERREIRA, 2013; BRASIL, 1978d).

Na tabela 1 representa os limites máximos toleráveis para uma jornada de trabalho de 44 horas semanais (os limites da ACGIH foram convertidos de 40 horas semanais para 44 horas por um fator de correção de acordo com a fórmula de Brief e Scala de 0,8807, enquanto os valores da NR -15 foram convertidos de 48 semanais para 44 horas por uma fator de correção de 1).

Os valores da tabela 1 não são para condições de horas extras, para isso a Portaria $\mathrm{N}^{\circ} 702 \mathrm{de}$ 28.05.2015 do Ministério do Trabalho e Emprego estabelece requisitos para a prorrogação de jornada em atividade insalubre, portanto nas atividades insalubres, quaisquer prorrogações de jornada, ou seja, as horas extras ( 2 horas por dia em um total de no máximo 10 horas diárias e 54 horas semanais) só poderão ser praticadas mediante autorização da chefia da unidade de segurança e saúde no trabalho da Superintendência Regional do Trabalho e Emprego correspondente (BRASIL, 2015).

Tabela 1 - Norma Regulamentador 15 do Ministério do Trabalho e ACGIH.

\begin{tabular}{lcc}
\hline \multicolumn{1}{c}{ Fumos } & NR-15 $\left(\mathbf{m g} / \mathbf{m}^{3}\right)$ & $\begin{array}{c}\text { ACGIH, Técnica NIOSH, Método } \\
\mathbf{7 3 0 3}\left(\mathbf{m g} / \mathbf{m}^{\mathbf{3}}\right)\end{array}$ \\
\hline Alumínio & - & 0,881 \\
Cobre & - & 0,1762 \\
Ferro, óxido $\left(\mathrm{Fe}_{2} \mathrm{O}_{3}\right)$ & - & 4,405 \\
Óxido de Magnésio & 1 & 8,81 \\
Manganês total & - & 0,01762 \\
Níquel total & - & 1,322 \\
Óxido de Zinco & - & 1,762 \\
Cádmio & - & 0,00881 \\
Cromo & 0,1 & 0,$4405 ; 0,04405 ; 0,00881^{*}$ \\
Chumbo & 7020 & 0,04405 \\
Dióxido de carbono & 43 & 7926,3 \\
Monóxido de carbono & 7 & 25,23 \\
Dióxido de nitrogênio & 0,16 & 0,3316 \\
Ozônio & & 0,$08651 ; 0,1384 ; 0,1730 * *$ \\
\hline
\end{tabular}

*Cr metal e compostos Cr III, compostos de Cr VI solúveis em água e insolúveis, respectivamente. **trabalho pesado, moderado e leve, respectivamente.

Fonte: Acgih, 2016; brasil, 1978d.

Um fator muito importante a ser considerado sobre a concentração e composição dos fumos metálicos, são os efeitos combinados de mais de um componente presente no ambiente que apresenta efeito toxicológico similares. Para dois componentes isolados a concentração está abaixo do valor máximo tolerável, mas quando combinados ultrapassa esse valor, trazendo prejuízos a saúde e integridade do trabalhador (PEIXOTO;FERREIRA, 2013).

\section{Danos a saúde humana}

$\mathrm{Na}$ área da saúde ocupacional, os principais problemas encontrados em relação a saúde dos trabalhadores no processo de soldagem são: distúrbios músculo esqueléticos; problemas respiratórios; efeitos da radiação UV; queimaduras por faíscas e respingos de solda; ruído; vibração; acidentes; visão (SILVA, 2003), entretanto nesse trabalho só será abordado sobre as doenças e problemas relacionais aos fumos metálicos e gases presentes no processo de soldagem. 
Os problemas provenientes aos fumos metálicos são geralmente de baixa gravidade, causando somente irritação no sistema respiratório ou febre. A febre pode ser temporária e é causada pelo zinco contido na superfície galvanizada, sendo considerada a febre muito comum entre os soldadores (AIHA, 1984).

Como as vias respiratórias são as principais portas de entrada de agentes nocivas, sendo as fossas nasais a primeira defesa contra esses agentes, fumos e gases atacam primeiro o trato respiratório, causando ação desconfortante, irritante, alérgica e/ou corrosiva. Apresentando como consequência da exposição prolongada, uma rinite alérgica (qualquer inflamação na mucosa nasal), representando este um problema de extensão mundial (BAGATIN;COSTA, 2006).

Mas em alguns casos, esses fumos metálicos podem trazer danos maiores ao organismo humano quando expostos com maior frequência/concentração. Com a exposição aos fumos metálicos acima dos limites permitidos pela legislação e a não utilização de EPI's/EPC's (Equipamentos de Proteção Coletiva), alguns destes compostos podem entrar no organismo e causar doenças, e também podem ser cumulativos dentro do organismo humano, trazendo sérios danos a saúde do trabalhador.

Como exemplo, pode-se citar o metal zinco que é um elemento essencial para os seres humanos, mas quando em elevadas concentrações no organismo pode levar a um quadro de intoxicação, causando vômitos, diarréias, cólicas, irritabilidade e lesões ao sistema respiratório. Esta é uma contaminação muito comum, pois o zinco é muito utilizado na indústria no processo de soldagem e galvanização. (BRITO FILHO, 1988). O óxido de zinco, magnésio e fumos de cobre causam a febre dos fumos metálicos, muito comum entres os trabalhadores da área de soldagem (ACGIH, 2013).

Outro caso é o níquel que, em exposição crônica, pode levar a câncer de pulmão, laringe e nasal (CASARETT;DOULL'S, 1986), mas em exposições agudas podem ficar retido nos pulmões na forma de fumos ou poeiras, provocando tosse, edema pulmonar e dermatite (IARC, 1987; ACGIH, 2013).

Outra doença muito comum entre os trabalhadores no processo de soldagem é a pneumoconiose, conhecida como siderose, que ocorre pelo depósito de óxido de ferro nos pulmões, sendo considerada benigna por não causar enfraquecimentos dos pulmões, nem proliferação de tecido fibroso (LUCAS; CARTER, 1999; BURGESS, 1997).

Os fumos metálicos de cromo podem ser gerados na forma de trivalente $\left(\mathrm{Cr}^{3+}\right)$ e hexavalente $\left(\mathrm{Cr}^{6+}\right)$, sendo este último bastante tóxico e é classificado como carcinogênico humano confirmado (A1) pela ACGIH. Enquanto que a forma menos agressiva, o trivalente, apresenta baixa toxicidade por não entrar nas células (COHEN et al., 1993; ANTONINI, 2003). Contudo outros autores revelam que o cromo trivalente quando em doses elevadas podem ser prejudiciais (USPHS, 1997). O cromo hexavalente, pode causar irritação e alergia na pele no trato respiratório superiores, levando a dispneia, tosse, dor no peito e em alguns casos câncer pulmonar (ACGIH, 2013; MORAES, 2013). Os principais sintomas de intoxicação são a pruridos nasais, rinorreia, epistaxe que evoluem para ulceração e perfuração do septo nasal (MORAES, 2013).

Os fumos metálicos de cádmio são extremamente tóxicos para a saúde dos empregados. Partículas menores que $5 \mathrm{~mm}$ de diâmetro são depositadas nos pulmões, sendo que $25 \%$ são fixas e $60 \%$ passa para a corrente sanguínea, acumulando principalmente nos rins, fígado e nos ossos podendo levar a disfunções renais e osteoporose (MORAES, 2013). Quando submetido a exposições agudas a altas concentrações por curtos períodos, o cádmio pode causar irritações, náuseas, vômitos, vertigem, diarréia, salivação e, exposições crônicas, causam dores no tórax, dispnéia, edema pulmonar, enfisema progressiva, azotemia, proteinuria, além de ser cancerígeno (GOSSEL, 1994). A concentração elevada de cádmio no organismo pode destruir o tecido testicular e as hemácias sanguíneas, sendo relacionado também ao câncer de pulmão e próstata pela International Agency for Research on Cancer (IARC) (MORAES, 2013). A ACGIH 
classifica o cádmio como carcinogênico humano suspeito (A2), onde existem dados conflitantes para classificar como A1, mas existe evidencias suficientes em experimentos com animais (ACGIH, 2013).

Tanto o cádmio quanto o manganês são classificados como aerodispersóides sistêmicos, pois esses agentes químicos têm a capacidade de atacar órgãos internos, enquanto que os fumos de chumbo são classificados como aerodispersóides mutagênico/teratogênicos, caracterizando por causar modificações celulares e alteração genéticas.

Além dos metais, os gases presentes no processo de soldagem podem causar danos à saúde dos trabalhadores dependendo do tempo e concentração de exposição, como os derivados do nitrogênio, oxigênio e ozônio, podendo causar lesões nas vias aéreas superiores (BAGATIN;COSTA, 2006).

Pesquisa realizada por Coggone e colaboradores (1994), concluiu que componentes metálicos dos fumos no processo de soldagem, juntamente com outros elementos, como o ozônio e óxidos de nitrogênio, afetam a mortalidade dos empregados. Sendo observado que, devido aos resíduos do processo de soldagem, o trabalhador fica mais susceptível a infecções pneumônicas, e que a pneumonia deveria ser considerada como doença ocupacional.

\section{Absorção de fumos metálicos no organismo humano}

A principal forma de entrada dos fumos metálicos no organismo é pela própria respiração, uma vez que os fumos ficam dispersos no ar. Contudo, o organismo humano possui defesas (proteções) que tentam impedir a entrada de partículas no organismo humano, mas existe uma faixa de tamanho que é retida.

Para os fumos, quando menor a partícula mais prejudicial pode ser, pois partículas muito pequenas podem entrar pelo sistema respiratório e se depositar nos alvéolos dos pulmões, em alguns casos de partículas menores, pode penetrar na corrente sanguínea.

Como os fumos são formados pelo resfriamento do vapor de soldagem com o ar, ocorre assim a condensação de vapor e são formados partículas do seu ponto de emissão que variam entre 0,01 a $0,1 \mu \mathrm{m}$. Quando alcançam a zona de respiração do soldador, essas partículas já se aglomeraram ficando com tamanho entre 1 a $2 \mu \mathrm{m}$ (NEDERMAN, 2016).

Partículas maiores que $5 \mu \mathrm{m}$ são depositadas no sistema respiratório (nariz, garganta, traquéia) e somente partículas entre 0,1 a $5 \mu \mathrm{m}$ conseguem penetrar nos pulmões (ficam retidos nos alvéolos pulmonares) (ANSCHAU, 2010). Nesse caso uma fração dessas partículas pode atravessar os alvéolos e penetrar na corrente sanguínea, depositando em ossos, tecidos, gorduras, órgãos e podendo até ser eliminada por mecanismos do corpo humano ou ser armazenado por décadas, sendo considerado esse último bio-acumulativo. Algumas desses compostos quando entram na corrente sanguínea pode ser biotransformado por qualquer órgão, mas é realizado principalmente o fígado (RUPPENTHAL, 2013).

A absorção de fumos metálicos e os danos causados pelo organismo têm várias implicações que podem causar resultados diferentes, pois as substâncias químicas podem reagir/acumular de forma diferente em cada organismo. Isto se deve a suscetibilidade de cada pessoa as concentrações impostas, podendo variar com idade, sexo, fatores genéticos, estilo de vida, ingestão de medicamentos e condições médicas preexistente (ex. agravamento de asma ou doença cardiovascular) (ACGIH, 2013).

Outras alterações à suscetibilidade a compostos químicos são referentes ao esforço exercido em cada atividade (ex. leve, moderado ou pesado), pois este parâmetro afeta a demanda cardiopulmonar (volume total de ar que entra nos pulmões), aumentando a quantidade de substância no organismo. A temperatura e umidade também podem influenciar na suscetibilidade e na absorção dos compostos, sendo que uma atividade exercida no calor favorece a abertura dos poros na pele e por essa nova via é absorvido mais facilmente os agentes químicos (ACGIH, 2013). 


\section{Equipamento de Proteção coletiva (EPC) e Individual (EPI)}

Em muitos casos o empregador não adota medidas de proteção para os funcionários, pagando somente o adicional de insalubridade, contudo na NR-15 relata que quando o trabalhador estiver exposto acima dos limites de tolerância previsto no anexo $\mathrm{N}^{\circ} 11$, é cabível o pagamento de insalubridade, entretanto não desobriga o empregador a adotar medidas de prevenção e controle que visem minimizar os riscos do ambiente de trabalho (BRASIL, 1978d).

De acordo com o Programa de Prevenção Respiratório (PPR) da Fundacentro os respiradores adequados para agentes químicos são aqueles que reduzem a exposição do empregado a valores abaixo do Limite máximo de tolerância, ou seja, a um Limite de Exposição Ocupacional (LEO). Para determinar o melhor respirador, deve-se inicialmente saber o Fator de Proteção Mínima Requerida (FPMR) e assim utiliza esse parâmetro para escolher o respirador com Fator de Proteção Atribuído (FTA) maior que o FPMR (TORLONI, 2016).

Além dos respiradores oferecerem proteção a exposição de agentes químicos, este deve também ser analisado em relação à tarefa, ao usuário e ao ambiente de trabalho, para que o usuário utilize por toda a jornada de trabalho sem desconforto.

Cada respirador tem suas características próprias, podendo ser classificado quanto ao seu uso: rotineiro, não-rotineiro, emergência e resgate, acrescentando o tempo de vida útil dos filtros, das baterias e da capacidade do reservatório de gás. Outro fator muitos importante em respiradores é o esforço físico durante a execução da atividade, pois uma atividade pesada de extremo esforço pode diminuir na metade a autonomia do respirador autônomo (TORLONI, 2016).

Na figura 1 é demonstrado que a escolha do tipo de respirador depende de algumas características, como o tipo de ambiente que está sendo exposto, os agentes químicos presentes e a concentração, pois em alguns casos a atmosfera pode ser imediatamente perigosa à vida ou à saúde (IPVS) e necessita de equipamento de respiração diferenciado.

Quando se trata de respiradores para o processo de soldagem, deve levar em consideração que esses equipamentos estão sujeitos a impacto de partículas quentes ou fundidas na qual pode causar danos ou ignição dos componentes do respirador (como o filtro), nesse tido de operação de soldagem não pode ser usado equipamento que contenham partes inflamáveis, sendo substituído por outro com maior resistência ao calor e à chama (TORLONI, 2016). 
Figura 1 - Classificação de respiradores.

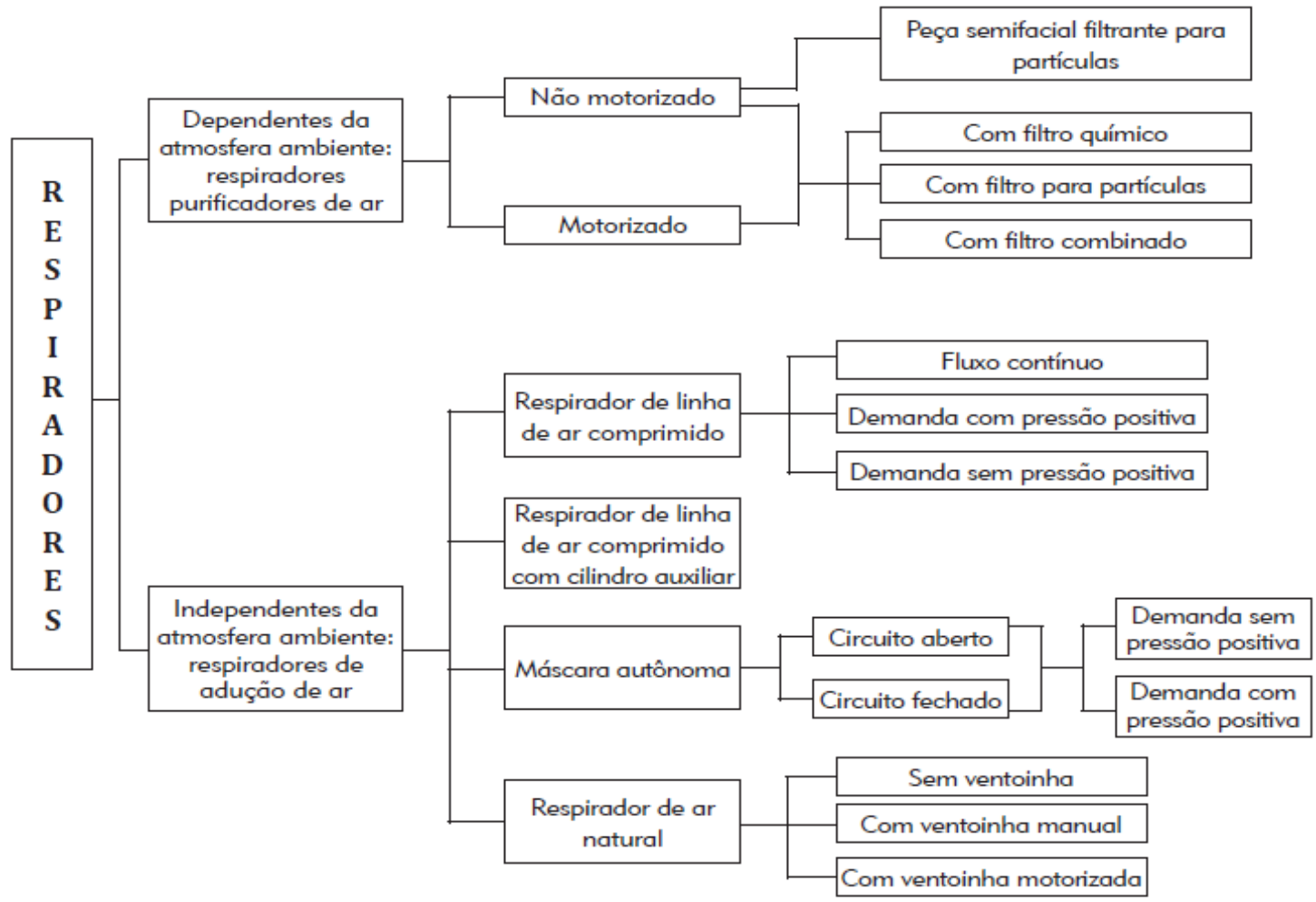

Fonte: Torloni, 2016.

Os filtros para partículas são classificados em P1, P2 e P3 e as peças semifaciais filtrantes em PFF1, PFF2 e PFF3. Para a atmosfera que contenha fumos metálicos, utilizar filtro classe P2 (ou peça semifacial filtrante para partículas PFF2 se o FPMR for menor que 10) (TORLONI, 2016). Para proteção contra fumos a Norma Regulamentadora 6 (NR - 6: Equipamentos de Proteção Individual -EPI) recomenda os tipos PFF2, PFF3, P2 e P3 (BRASIL, 1978a). Estes são os mais usados, entretanto pode-se usar ainda respirador purificador de ar motorizado, sendo este mais caro em relação aos demais.

Além do respirador, outros EPI's são recomendados para atividade de soldagem pela ITSEMAP: Máscara de solda (contra impactos de partículas, laminação intensa e radiação ultravioleta e infravermelha), avental de raspa de couro; luvas de raspa de couro; perneira de raspa de couro; calçado de segurança com biqueira de aço ou de resina; blusão de raspa de couro para soldas; capuz de brim (ITSEMAP, 2005; BRASIL, 1978a).

Caso seja necessário, devem-se utilizar Equipamentos de Proteção Coletiva (EPC) para garantir uma completa proteção ao empregado contra os riscos no ambiente de trabalho. Os principais tipos de EPC para prevenir que os fumos metálicos presentes no ar chegue no sistema respiratório do soldador são: sistema de exaustão, ventilação e filtragem.

O mais utilizado nas empresas de soldagem é a exaustão, sendo que pode ser subdividida em braço extrator e tochas aspirantes. O braço extrator é utilizado junto ao processo de soldagem como uma unidade individual, podendo ser acoplado diretamente no exaustor ou em sistema de exaustão centralizada (onde são acoplados vários braços ao longo da linha) ou ainda pode ser móvel. O tipo tochas MIG/MAG aspiradas possuem seu próprio sistema de mangueiras flexíveis que realizam a exaustão dos fumos, apresentando eficiência entre 70 a $98 \%$ e sendo ideal para processos de soldagem com automatizados com robôs (ANSCHAU, 2010). 
Os EPC's apresentam como desvantagem o alto custo de instalação e de operação, pois necessita de uma vazão de gás alta para retirada dos gases e um processo de filtração desses gases para ser lanchados na atmosfera, necessitando assim de manutenções e trocas.

Entretanto apresenta vantagens incomparáveis em relação a remoção dos fumos e gases resultantes no processo de soldagem, estudo realizado por Führ (2012) em uma empresa de soldagem, constatou a significativa redução dos fumos metálicos com a presença do exaustor durante a atividade de soldagem. Foram avaliados os agentes químicos ferro, manganês, cádmio, chumbo, cobre, cromo (III), zinco e níquel, obtendo redução na concentração de $80,5 \%, 85,7 \%, 56,7 \%, 60,5 \%, 77,3 \%, 80,5 \%, 40,4 \%$ e 96,1\%, respectivamente.

\section{Prevenção (PCMSO e PPRA)}

O Programa de Prevenção de Riscos Ambientais (PPRA) é o documento obrigatório para todos empregadores e instituições que admitam trabalhadores como empregados, visando a identificação dos riscos ambientais como os agentes físicos, químicos e biológicos. Desta forma para prevenir problemas na saúde dos trabalhadores, deve-se realizar a antecipação, reconhecimento, avaliação e controle dos riscos ambientais e assim realizar a elaboração e implementação do PPRA (como disposto na NR - 9). Com o PPRA é possível identificar os principais riscos envolvidos em cada atividade e aplicar medidas de controle, adotando os EPC's e EPI's necessários para cada ambiente que o empregado esteja exposto (BRASIL, 1978c).

Para a elaboração do PPRA deve ser considerado os limites de exposição da NR 15, entretanto na ausência desta, deve-se utilizar os valores limites de exposição ocupacional adotados pela ACGIH, como disposto no item 9.3.5.1 da NR - 9 (BRASIL, 1978c).

O PPRA deve está articulado com o Programa de Controle Médico de Saúde Ocupacional (PCMSO), como previsto na NR - 7. Este programa tem o intuito de prevenção, rastreamento e diagnóstico precoce dos agravos à saúde relacionados ao trabalho, além da identificação da existência de doenças profissionais e danos irreparáveis a saúde dos trabalhadores (BRASIL, 1978b).

No desenvolvimento do PCMSO é obrigatório a realização dos exames admissionais, periódicos, de retorno de trabalho, de mudança de função e demissional, sendo que para a exposição de agentes químicos listados no quadro I da NR-7 deve ser realizado os exames complementares para o controle biológico da exposição de agentes químicos como cádmio, chumbo e cromo. Para o cádmio deve ser feito análise em espectrofotometria de absorção atômica e o IBMP (Indicador Biológico Máximo Permitido) é de $50 \mu \mathrm{g} / \mathrm{g}$ de creatinina para análise da urina como material biológico, enquanto que o cromo o método e material biológico são os mesmos, mas com IBMP de $30 \mu \mathrm{g} / \mathrm{g}$ de creatinina. Já o chumbo o método analítico é o espectrometria Ultravioleta/visível com IBMP de $10^{*} 10^{3} \mu \mathrm{g} / \mathrm{g}$ creat. com material biológico urina, mas pode ser feito outros método com sangue (espectrofotometria de absorção atômica e hematofluorômetro) (BRASIL, 1978b).

No quadro II da NR 7 está listado os parâmetros para monitoramento da exposição ocupacional a alguns riscos á saúde, sendo que os trabalhadores expostos a aerodispersóides existem exames complementares de Telerradiografia do tórax e Espirometria (BRASIL, 1978b).

\section{Amostragem da identificação de agentes químicos}

Para uma melhor identificação dos agentes químicos presentes no ambiente de trabalho, deve-se levar em conta alguns parâmetros principais como o tempo de amostragem, quantidade das amostras, os tipos de amostragem, o amostrador a ser utilizado e o método de coleta (PEIXOTO e FERREIRA, 2013). 
O tempo de amostragem depende do volume de contaminante a ser coletado e existem normas especificas como a NHO 08, NR 15 e NIOSH. O tempo para se realizar a amostragem deve ser suficiente para coletar um volume de ar adequado, assim obter uma quantidade suficiente para realizar a análise (PEIXOTO;FERREIRA, 2013).

A quantidade vai depender da variedade de exposições que existe no ambiente de trabalho, podendo ser necessárias avaliações em diferentes dias e horários (PEIXOTO;FERREIRA, 2013).

Já o tipo de amostragem pode ser pessoal que acompanha o trabalhador na sua jornada de trabalho, sendo o dispositivo acoplado perto da região respirável. Pode ser do tipo ambiental também onde o amostrador fica fixado em um determinado ponto no ambiente de trabalho. $\mathrm{O}$ tipo de amostragem pode ser classificado ainda como a duração, podendo ser instantâneas (curta duração, inferior a 5 minutos) e contínuas (períodos longos de 30 minutos) (PEIXOTO;FERREIRA, 2013).

O amostrado a ser utilizado são divididos em passivos e ativos. Nos amostradores do tipo ativo, ocorre a passagem de um determinado volume de ar de forma forçada através de uma bomba de fluxo, enquanto a passiva a passagem ocorre simplesmente pela difusão do gás (passagem da substância de uma região mais concentrada para uma menos concentrada) (PEIXOTO;FERREIRA, 2013).

Os métodos de coleta podem ser o ar total onde todo o volume coletado é utilizado para fazer a análise ou pode ser com separação dos contaminantes, onde o contaminante é separado por um filtro para posterior análise em laboratório. Nos dois casos a análise deve ser feita o mais rápido possível, pois o contaminante a ser analisado pode sofrer dessorção pelas paredes do recipiente e assim diminuir o composto na amostra (PEIXOTO;FERREIRA, 2013).

\section{CONCLUSÕES}

O processo de soldagem oferece vários riscos para os trabalhadores, sendo um dos principais o risco químico devido à formação de fumos metálicos durante o processo. Estes fumos são dispersos no ambiente de trabalho sendo aspirados pelo trato respiratório e causando diversos problemas à saúde do trabalhador, sendo o pior deles a ação cancerígena de alguns agentes químicos.

Podem-se adotar medidas para que o ambiente de trabalho se torne salubre. Existem algumas normas como a OHSAS 18001 e ISO 14001 (que compreendem respectivamente em Sistemas de Gestão de Segurança e Saúde Ocupacional e Gestão Ambiental) que podem auxiliar na melhor gestão do ambiente de trabalho. Desta forma, é possível reduzir acidentes e/ou doenças ocupacionais obtendo como consequência a redução do custo do produto final e o aumento da produtividade, uma vez que terá menos interrupções durante o processo.

\section{REFERÊNCIAS}

ACGIH - American Conference of Governmental Industrial Hygienists. Limites de exposição ocupacional (TLVs®) para substâncias químicas. 2016. Disponível em: <https://www.osha.gov/dsg/annotated-pels/tablez-1.html>. Acesso em: 27 de jan. de 2017.

ACGIH - American Conference of Governmental Industrial Hygienists. Limites de exposição ocupacional (TLVs®) para substâncias químicas e agentes físicos e índices biológicos de exposição (BEIs®). Tradução: Associação Brasileira de Higienistas Ocupacionais - ABHO, São Paulo - SP, 2013. 
AMERICAN INDUSTRIAL HYGIENE ASSOCIATION - AIHA. Arc Welding and Your Health. A Handbook of Health Information for Welding. Fairfax: AHIA Publications, 1984, 16 p.

ANSCHAU, L. D. Análise de fumos de soldagem, sistemas de proteção e desenvolvimento de protótipo para estudo da emissão de fumos de soldagem para processo MIG/MAG. Trabalho de conclusão do curso de Engenharia mecânica da Universidade Regional do Noroeste do Estado do Rio Grande do Sul - UNIJUÍ, Panambi, 2010.

ANTONINI, J. M. Health effects of welding. Critical Reviews in Toxicology, v. 33 (1), p. 61 - 103, 2003.

BAGATIN, E.; COSTA, E. A. Da. Doença das vias aéreas superiores. Jornal Brasileiro de Pneumologia, 32 (Supl 1):p. 17-26, 2006.

BRASIL. Ministério do Trabalho e Emprego. Portaria no 702, de 28 de maio de 2015. Prorrogação de jornada em atividade insalubre. Diário Oficial da República Federativa do Brasil, Brasília, DF, 28 mai. 2015. Disponível em:

<http://acesso.mte.gov.br/data/files/FF8080814DB129A5014DB98F83FC53F6/Portaria\%20MTE\%20n.\% C2\%BA\%20702\%20(Jornada\%20de\%20Trabalho\%20em\%20Atividade\%20Insalubre).pdf >. Acesso em: 27 jan. 2017.

BRASIL. Ministério do Trabalho e Emprego. Portaria no 3.214, de 08 de junho de 1978. NR 06: Equipamento de Proteção Individual - EPI. Diário Oficial da República Federativa do Brasil, Brasília, DF, 06 jul. 1978a. Disponível em: < http://trabalho.gov.br/images/Documentos/SST/NR/NR6.pdf>. Acesso em: 28 jan. 2017.

BRASIL. Ministério do Trabalho e Emprego. Portaria no 3.214, de 08 de junho de 1978. NR 07: Programa de controle médico de saúde ocupacional. Diário Oficial da República Federativa do Brasil, Brasília, DF, 06 jul. 1978b. Disponível em: 〈http://trabalho.gov.br/images/Documentos/SST/NR/NR7.pdf〉. Acesso em: 27 jan. 2017.

BRASIL. Ministério do Trabalho e Emprego. Portaria $n^{\circ}$ 3.214, de 08 de junho de 1978. NR 09: Programa de prevenção de riscos ambientais. Diário Oficial da República Federativa do Brasil, Brasília, DF, 06 jul. 1978c. Disponível em: 〈http://trabalho.gov.br/images/Documentos/SST/NR/NR09/NR-09-2016.pdf〉 Acesso em: 17 de Nov. 2016.

BRASIL. Ministério do Trabalho e Emprego. Portaria n 3.214, de 08 de junho de1978. NR 15: atividades e operações insalubres. Diário Oficial da República Federativa do Brasil, Brasília, DF, 06 jul. 1978d. Disponível em:<http://trabalho.gov.br/images/Documentos/SST/NR/NR15/NR15-ANEXO15.pdf> Acesso em: 18 de Nov. 2016.

BRITO FILHO, D. Toxicologia humana e geral. 2.ed. Rio de Janeiro: Atheneu, 1988. 678p.

BURGESS, W. A. Identificação de possíveis riscos à saúde do trabalhador nos diversos processos industriais. Tradução Ricardo Baptista. Belo Horizonte: Ergo Editora, 1997.

CASSARETT, A.; DOULL'S, D. Toxicology: the basic science of poisons. 5.ed. USA: McMillan Publishing, 1986. 1111p.

COGGON, D.et al. Lobar Pneumonia: an Occupational Disease in Welders. The Lancet, v. 344, p. 41 43, Jul, 1994.

COHEN, M. D.et al. Mechanisms of chromium carcinogenicity and toxicity. Critical Reviews in Toxicology, v. 23, p. 255-281, 1993.

COLACIOPPO, S. Avaliação da Exposição Profissional a Fumos Metálicos em Operações de Solda. Revista Brasileira de Saúde Ocupacional, n. 49 - Vol. 13, p. 50-77, 1985. 
FÜHR, T. A. Reconhecimento e avaliação dos riscos ambientais gerados nos processos de soldagem de uma empresa do segmento metal mecânico. Monografia do Curso de Pós-Graduação Lato Sensu em Engenharia de Segurança do Trabalho da Universidade Regional do Noroeste do Estado do Rio Grande do Sul, Ijuí-RS, 2012.

GAREIS, B. A Soldagem, Simples Como Ela É. Coleção Manuais Técnicos, n. 9. Recife: SACTES, 1994, 223 p.

GOLDMAN, C. F. Análise de acidente de trabalho ocorridos na atividade da indústria metalúrgica e metal-mecânica no estado do Rio Grande do Sul em 1996 e 1997: Breve interligação sobre o trabalho do soldador. Dissertação (Mestrado) - Pós-Graduação em Engenharia de Produção da Universidade Federal do Rio Grande do Sul, Porto Alegre - RS, 2000, 135 p.

GOSSEL, T. A. Principles of Clinical Toxicology, 2th edition, N.Y., Raven Press, 1994.

HEWITT, P. Occupational Health in Metal Arc Welding. Welding in the World/Le Soudage Dans Le Monde, Roissy, v. 43, n. 5, p. 12-19, 1999.

IARC - International Agency for Research on Cancer. Overall evaluation of carcinogenicity: an updating of IARC monographs. In: IARC Monographs on the Evaluation of Carcinogenic Risks to Humans, World Health Organization, Ed., Geneva, pp. 165- 168, 1987.

ITSEMAP DO BRASIL. Serviços Tecnológicos MAPFRE. Guias básicos de segurança: solda. n. 7 , 2005.

KADEFORS, R.; LARING, J. Ergonomics and Welding Workplace Design. In: BRUNE, D. (Ed.) The Workplace, Volume 2: Major Industries and Occupations. Geneva: ILO, p. 478 - 490,1997.

LOPES, A. L. Segurança Química. São Paulo: Ed LTR, 2007.

LUCAS, W.; CARTER, G. Factors to Be Considered in the Safe Use of Arc and Oxi Fuel Welding Processes. Welding in the World/Le Soudage Dans Le Monde, Roissy, v. 43, Supplementary Issue: THE HUMAN FACTOR AND ITS ENVIRONMENT, p. 31 - 43, 1999.

LYTTLE, K. A. Decrease Fume, Increase Productivity: Optimized Consumables Selection for an Improved Working Environment and Reduced Welding Costs. Welding in the World/Le Soudage Dans Le Monde, Roissy, v. 43, Supplementary Issue: THE HUMAN FACTOR AND ITS ENVIRONMENT, p. 75 - 84, 1999.

MAESTRI, A. A.; VITALI, C. A. Aspectos negativos dos fumos de soldagem: prevenção e soluções para salvaguardar a saúde do trabalhador. (Trabalho de conclusão de curso, Especialização em Segurança do Trabalho). Universidade Estadual de Ponta Grossa. Ponta Grossa, 49 f., 2005.

MAGRINI, R. O. Segurança do Trabalho na Soldagem Oxiacetilênica. 2.ed. São Paulo: FUNDACENTRO, 1999. $72 \mathrm{p}$.

MORAES, M. V. G. Doenças ocupacionais - Agentes: físico, químico, biológico, ergonômico, $1^{\mathrm{a}}$ ed, $4^{\circ}$ reimpressão. São Paulo: Érica, 2013.

NEDERMAN. Manual de saúde para soldadores: Riscos e soluções para os fumos de solda. Disponível em: 〈http://www.mkfiltragem.com.br/informativos/Riscos.pdf > Acesso em: 21 de dezembro de 2016.

PEIXOTO, N. H.; FERREIRA, L. S. Higiene ocupacional III. Universidade Federal de Santa Maria, Colégio Técnico Industrial de Santa Maria, Rede e-Tec Brasil, 2013.

RUPPENTHAL, J. E. Toxicologia. Universidade Federal de Santa Maria, Colégio Técnico Industrial de Santa Maria; Rede e-Tec Brasil, 2013. Santa Maria-RS, 128 p., 2013. 
SILVA, M. L. F. Da; SIQUEIRA, A. M. A. Analise qualitativa dos riscos químicos inerentes á saúde no ambiente laboral que abrange o processo de soldagem com eletrodos revestidos. XXXIV Encontro Nacional de Engenharia de Produção, Curitiba, PR, Brasil, 2014.

SILVA, S. A. Da. Análise ergonômica do trabalho do soldador: Contribuição para projetação ergonômica. Programa de Pós-Graduação em Engenharia de Produção (Trabalho de Conclusão do Curso de Mestrado Acadêmico em Engenharia) - Universidade Federal do Rio Grande do Sul, Porto Alegre, 2003.

SOUZA, R.et al.. Lesão por inalação de fumaça. Artigo de revisão. Jornal Brasileiro de Pneumologia, 30 (5), p. $557-565,2004$.

TORLONI, M. Programa de proteção respiratória: recomendações, seleção e uso de respiradores. 4. ed. - São Paulo: Fundacentro, 2016. Disponível em: <file:///C:/Users/joaop/Downloads/PPR1000_Portal.pdf> Acesso em: 27 de jan. 2017.

USPHS - U.S. Public Health Service. Toxicological profile for zinc on CD-ROM. Agency for Toxic Substances and Disease Registry. U.S. Public Health Service, 1997.

VIDAL, M. S.; CARVALHO, J. M. F. C. Segurança Química em Laboratórios de Pesquisa. Circular Técnica, Embrapa, Campina Grande - RS, 2003. 